\title{
Study in Correlation between Senile Cataract and Serum 25-Hydroxyl Vitamin D Insufficiency
}

\author{
Sujata Charel ${ }^{1}$, Janki Brahmbhatt ${ }^{2}$, Jeet Patel $^{2}$, Robin Jain $^{3}$, Nirathya Anisha P. ${ }^{2}$, Niklank Mehta ${ }^{4}$ \\ ${ }^{1}$ Assistant Professor, ${ }^{2} 2^{\text {nd }}$ Year Resident, ${ }^{3} 3^{\text {rd }}$ Year Resident, ${ }^{4} 2^{\text {nd }}$ Year Resident, \\ Department of Ophthalmology, SBKS \& MIRC, Sumandeep Vidyapeeth
}

\begin{abstract}
Background: Study in correlation between Senile cataract and Serum 25-Hydroxyl Vitamin D Insufficiency. Mean Value of vitamin -D less than $10 \mathrm{ng} / \mathrm{ml}$ seen in group-1 which show severe deficiency. Mean Level of vitamin-D in group-2 $15-24 \mathrm{ng} / \mathrm{ml}$ which show mild to moderate deficiency. There was a statistically significant difference in both groups. (p value- $<0.03)$

Method: $25 \mathrm{OH}$ D level were examined in 300 patients who had cataract and 280 normal patients of both sex were examined using the technology name as chemiluminescent micro particle immunoassay (CMIA).

Conclusion: In normal patients have below the reference levels while a severe insufficiency of 25-OH D levels in cataract patients. These shows the role of $25-\mathrm{OH}$ D deficiency in senilecataract patients.
\end{abstract}

Keywords: Senile cataract, 25 hydroxyl Vitamin D, Chemiluminescent micro particle immunoassay (CMIA).

\section{Introduction}

India is a developing countries, Eye problems specially refractive problems is a leading cause in worldwide. ${ }^{[1]}$ Visual deterioration is commonest risk factors for day to day life time functions and work and those are at very high risk of socially isolated. ${ }^{[2,3]}$. In general if we see, females are more prone to develop cataract than men. ${ }^{[4]}$. In age related disease, visual deterioration is a major non modifiable risk factors. ${ }^{[5]}$ Factors which are modifiable risk factors are smokers ${ }^{[6,7]}$ chronic liquor use ${ }^{[8]}$ fatness ${ }^{[9]}$, malnutrition and chemicals ${ }^{[10]}$ which increase redness and oxidative stress. Vitamin D have a anti inflammatory properties ${ }^{[11]}$, which has a protective role against cataract formation ${ }^{[12]}$. This study includes correlation between $25-\mathrm{OH} \mathrm{D}$ and cataract development ${ }^{[13]}$ help us early identification of any risk factor which help us to delay the onset of cataract.

\section{Material and Method}

The place of study was managed in the Ophthalmology Department of Dhiraj Hospital, Sumandeep Vidyapeeth, MI \& RC, Piparia, Vadodara from August 2019 to January 2020 of 580 cataract

\section{Corresponding Author:}

\section{Dr. Janki Brahmbhatt}

M.S. Ophthalmology, Resident $2^{\text {nd }}$ Year

Department of Ophthalmology, SBKS MI \& RC

Sumandeep Vidyapeeth Deemed to be University, Piparia39170,Vadodara, Gujarat

e-mail: dr.janki91@gmail.com

Mobile No.: 9601893767,9773475310 patients who were undergone for cataract surgery. Inclusion criteria were patients with age more than 50 years and senile cataract that includes cortical cataract, nuclear and sub capsular cataract. Exclusion criteria were : Patient on any systemic medication like Aspirin or any blood thinner, any anti-inflammatory or steroid use of medication, any recent ocularsurgery, if on any anti diabetic medication. Informed consent was obtained from both groups. The control group was taken from the routine out patient clinic who have no cataract. Grading of lens was done byLens opacity classification system (LOCS) that includes both nuclear and cortical cataract $^{[14]}$. In total, the case group included 300 patients who having senile cataract and the control group included 280 normal individual. From both the groups, $3 \mathrm{ml}$ blood sample was collected in a plain vacutainer. After 
centrifugation of whole blood after clot formation for 5 minutes at $3000 \mathrm{rpm}$ all serum sample was assessed and stored freezing for 2 months at -80 degree. A technology which was used to estimate the $25-\mathrm{OH}$ vitamin $\mathrm{D}$ level is chemiluminescent micro particle immunoassay (CMIA). Serum Sample and pretreatment reagent both are mixed. To create a reaction mixture, pretreated sample was mixed with diluents and para magnetic anti vitamin D coated micro particles. Mixing of all trigger solutions there action developed was chemiluminescent reaction that was measured as Relative Light Units (RLUs). The level of 25-OH D in every groups was stratified by 3 breakpointsless than $30 \mathrm{ng} / \mathrm{ml}$ (vitamin D insufficiency), less than $20 \mathrm{ng} / \mathrm{ml}$ (vitamin D deficiency), and less than $10 \mathrm{ng} / \mathrm{ml}\left(\right.$ vitamin D severe deficiency) ${ }^{[15]}$.

Statistical Analysis: Quantitative data were expressed in terms of means with or without standard deviation, median, and range. Qualitative data were expressed in number. The chi-squared test used for comparison between two groups.

\section{Result and Discussion}

In the group- 1 that include patients having senile cataract, 300 patients were included,from that 100 patients had a cortical cataract, and 80 patients had a posterior subcapsular cataracts, 120 patients had a nuclear cataract while the group-2 that include normal individual had 280 patients. There is no statistical difference in term of age and sex in both groups. The 25-OH D mean level was low in group 1 which was less than $10 \mathrm{ng} / \mathrm{ml}$, where in group-2 had a mild-to moderate deficiency in range between 15-24 ng/ml. High statistically significant difference was noticed between both groups.(p value- $<0.03$ ) The nuclear cataract shows lowest level of 25-OH D and the posterior sub capsular type cataract has the highest value. The study shows undesirable correlation that with increasing age and serum 25-OH D level change.

\section{Age Distribution:}

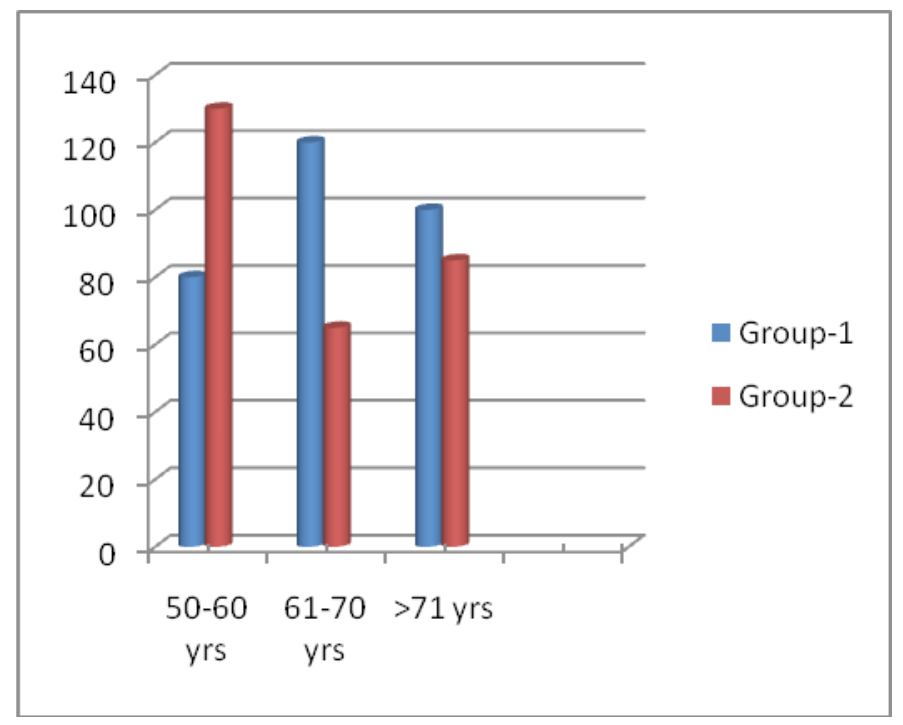

Undesirable relationship with $25 \mathrm{OH} \mathrm{D}$ deficiency seen in macular degeneration ${ }^{[16]}$ diabetic related ocular problems $^{[17]}$ uveitis and keratoconjunctivitis sicca. Result of this study shows serum 25-OH D level low in both groups. In group 1 level of $25-\mathrm{OH} \mathrm{D}$ much lower than stated levels of severe deficiency. In the group 2, 25-OH D level was lower which show mild to moderates vitamin D deficiency compared to standard values and also lower than the levels in other studies which were conducted in different regions like in Asia and USA. ${ }^{[18]}$. To obtained normal values of vitamin-D level people have to work in day time so have more sunlight exposure which help them to have normal range of 25-OH D level. ${ }^{[20]}$. Another possibility is different lifestyle with different dietary supplements. In a Korean study ${ }^{[21]}$ if we compare level of vitamin D in cataract patients in both sex group was 16 and $14 \mathrm{ng} / \mathrm{ml}$ in men and women respectively. This things indicates 
that vitamin D value vary from different people, state, region and country according to exposure of sunlight ${ }^{[22] \text {. }}$ Vitamin D levels has no correlation with age. Although, studies done in Korea and Thailand showed the result that as young people has more work in indoor activities so less sun exposure so less vitamin D level as compare with old age people ${ }^{[23,24]}$, Role of Vitamin $\mathrm{D}$ that reduces inflammatory mediators and shows antioxidative properties ${ }^{[29-31]}$ that protect against cataract development. It was advised that increased vitamin D supplements may prevent cataractogenesis ${ }^{\text {[21]. }}$.

\section{Conclusion and Acknowledgement}

We conclude that in both the group serum 25-O D level were low than standard Level. In all type of cataract particularly. Nuclear cataract has lowest $25-\mathrm{OH}$ D levels. These results see the role of deficiency of 25OHD in senile cataract patient.

Ethical Clearance: Taken from HRRP committee

\section{Source of Funding: Nil}

\section{Conflict of Interest: Nil}

\section{References}

1. Bray F, Ferlay J, Soerjomataram I, Siegel RL, Torre LA, Jemal A. Global cancer statistics 2018: GLOBOCAN estimates of incidence and mortality worldwide for 36 cancers in 185 countries. CA: a cancer journal for clinicians. 2018 Nov;68(6):394424.

2. McLean G, Guthrie B, Mercer SW, Smith DJ. Visual impairment is associated with physical and mental comorbidities in older adults: a cross-sectional study. BMC medicine. 2014 Dec 1;12(1):181.

3. Rubin GS, Bandeen-Roche K, Huang GH, Munoz B, Schein OD, Fried LP, West SK. The association of multiple visual impairments with self-reported visual disability: SEE project. Investigative ophthalmology \& visual science. 2001 Jan 1;42(1):64-72.

4. Mousa A, Courtright P, Kazanjian A, Bassett K. Prevalence of visual impairment and blindness in Upper Egypt: a gender-based perspective. Ophthalmic epidemiology. 2014 Jun 1;21(3):1906.

5. Delcourt C, Cristol JP, Tessier F, Leger CL, Michel F, Papoz L, POLA Study Group. Risk factors for cortical, nuclear, and posterior subcapsular cataracts: the POLA study. American journal of epidemiology. 2000 Mar 1;151(5):497-504.

6. West S, Munoz B, Schein OD, Vitale S, Maguire M, Taylor HR, Bressler NM. Cigarette smoking and risk for progression of nuclear opacities. Archives of ophthalmology. 1995 Nov 1;113(11):1377-80.

7. Tan JS, Wang JJ, Younan C, Cumming RG, Rochtchina E, Mitchell P. Smoking and the longterm incidence of cataract: the Blue Mountains Eye Study. Ophthalmic epidemiology. 2008 Jan 1;15(3):155-61.

8. Cumming RG, Mitchell P. Alcohol, smoking, and cataracts: the Blue Mountains eye study. Archives of ophthalmology. 1997 Oct 1;115(10):1296-303.

9. Kuang TM, Tsai SY, Hsu WM, Cheng CY, Liu JH, Chou P. Body mass index and age-related cataract: the Shihpai Eye Study. Archives of Ophthalmology. 2005 Aug 1;123(8):1109-14.

10. Mares JA, Voland R, Adler R, Tinker L, Millen AE, Moeller SM, Blodi B, Gehrs KM, Wallace RB, Chappell RJ, Neuhouser ML. Healthy diets and the subsequent prevalence of nuclear cataract in women. Archives of ophthalmology. 2010 Jun 1;128(6):738-49. 